\title{
Hazard estimation from Radiofrequency Radiation in a Nigerian Teaching Hospital from nearby GSM Base-Stations
}

\author{
${ }^{1}$ Ajiboye Y., ${ }^{2}$ Farai I.P., ${ }^{3}$ Ayinmode B.O., ${ }^{1}$ Alao O.A \\ ${ }^{\prime}$ (Department of Physics, AfeBabalola University, Ado-Ekiti, Nigeria) \\ ${ }^{2}$ (Department of Physics, University of Ibadan, Nigeria) \\ ${ }^{3}$ (Radiation and Health Physics Research Laboratory, Department of Physics, University of Ibadan, Nigeria)
}

\begin{abstract}
Increasing competition between GSM service providers and several calls for improvement of their quality of service from members of the public has led to proliferation of base station (BTS) masts in Nigeria. Consequently, there is an increase in the risk of radiation hazard due to exposure of the public to radiofrequency radiation from the BTS antennae. This study is aimed at estimating the radiation hazard due to electric field intensity from BTSs.Electric field intensity measurements due to different GSM Operators were taken at thirty sites in the $900 \mathrm{MHz}$ and $1800 \mathrm{MHz}$ frequency bands. The maximum instantaneous electricfield intensities of $301.05 \pm 63.85 \mathrm{mV} / \mathrm{m}$ and $241.49 \pm 57.00 \mathrm{mV} / \mathrm{m}$ were obtained for GSM900 and GSM1800 respectively. Estimation of the specific energy absorption rate (SAR) yield $39.00 \mu \mathrm{W} / \mathrm{kg}$ and $34.80 \mu \mathrm{W} / \mathrm{kg}$ for the skin, while that of the brain yield $33.90 \mu \mathrm{W} / \mathrm{kg}$ and $32.70 \mu \mathrm{W} / \mathrm{kg}$ for GSM 900 and GSM 1800 respectively. The skin penetration depth for the worst case of exposure was obtained as $4.16 \mathrm{~cm}$. Exposures in the study area are below the ICNIRP reference level.
\end{abstract}

Keywords: GSM, BTS, radiofrequency, SAR, Penetration depth

\section{Introduction}

Performance evaluation of GSM operators in Nigeria have suggested the need for operators to build more base transceiver stations in order to increase their network coverage[1]. This development has necessitated the proliferation of the erection of base station antennas, and consequently, increased level of electromagnetic fields in the environment. The possible health effects of electromagnetic radiations have for some time now been a popular subject of interest. This is attributable to the fact that if there is any detectable detrimental effect, no matter how small, it could be very important due to the widespread use of mobile phones, the monumental numbers of people exposed to radiofrequency radiation on a daily basis, and the social, economic and health impacts this could have[2].

When electromagnetic radiations (EMRs) in the microwave region pass through a medium, they lose energy to the medium. The intensity of the electromagnetic field decreases exponentially with respect to the depth of the absorbing medium[3]. The effectiveness of absorbers for EMRs such as the human skin is determined by the depth of penetration of the radiation in the material. The penetration depth $\delta$ is the depth within the absorber at which the energy of the incident radiation decreases to one tenth of its incident value[4]. It is given as the inverse of the absorption coefficient $\alpha$. That is:

$$
\delta=\frac{1}{\alpha} \ldots
$$

such that

$$
\alpha=\omega \sqrt{\frac{\mu \epsilon}{2}}\left[\left\{1+\left(\frac{\sigma}{\omega \epsilon}\right)^{2}\right\}^{1 / 2}-1\right]^{1 / 2} \ldots
$$

where $\omega=2 \pi f$ is the angular frequency, $\sigma$ is the conductivity of the absorbent, $\epsilon$ and $\mu$ are permittivity and permeability of the absorbent respectively.

Various health effects have been associated with electromagnetic radiations. Several researches have chiefly identified the thermal effects of the EMR $[4,5]$. Although several studies have suggested a link between electromagnetic radiation and increased risk of health deficiencies such Leukaemia, testicular cancer, cancer of eye, etc., but collectively, no convincing evidence have been provided[6,7]. Many other reports have it that exposure of organisms to radiofrequency radiations do not have any significant effect on some major biological indices $[8,9]$ while others observed some cellular alterations in exposed organisms but suggested need for further investigation[10].

Restrictions on exposure to time varying electromagnetic fields are set based on established health effects[7]. The physical quantities used in setting such restrictions are frequency dependent and include current density (J), specific energy absorption rate (SAR) and power density (S). For spatial exposure to the 
electromagnetic field in the far field of a radiating antenna, the power density, which is the rate of energy flow per unit area of space and measured in Watts per square meters, can readily be measured since the relationship between the electric and magnetic fields are known.

Radiation survey meters are usually calibrated to read the far field power density corresponding to the measured electric field intensity[11]. This relationship is given as:

$$
S=\frac{|E|^{2}}{\eta}=\eta|H|^{2} \ldots
$$

where $\mathrm{E}$ and $\mathrm{H}$ are the root mean square values of the electric and magnetic field strengths respectively and $\eta$ is the wave impedance which is $377 \mathrm{Ohm}$ in free space[12]. Table 1 presents the ICNIRP reference levels for general public exposure to time varying electromagnetic fields.

Table 1: ICNIRP reference levels for general public exposure to time varying electric and magnetic fields

\begin{tabular}{lccc}
\hline Frequency (MHz) & Electric Field Strength $(\mathbf{V} / \mathbf{m})$ & Magnetic Field Strength $(\mathbf{A} / \mathbf{m})$ & $\begin{array}{c}\text { Equivalent Power Density } \\
\left(\mathbf{W} / \mathbf{m}^{2}\right)\end{array}$ \\
\hline $400-2000$ & $1.375 \sqrt{\mathrm{f}}$ & $0.0037 \sqrt{\mathrm{f}}$ & $\mathrm{f} / 200$ \\
$2000-3000$ & 61 & 0.16 & 10
\end{tabular}

Animportant physical quantity used in setting restrictions on exposure to time varying electromagnetic fields is the specific energy absorption rate (SAR) expressed in watts per kilogram (W/Kg). The SAR is an important dosimetric quantity for non-ionizing radiations. It is the time derivative of dissipated energy per unit mass of an exposed body or the absorbed power per unit mass of tissue. It is usually averaged over the whole body or over a tissue mass of $1 \mathrm{~g}$ or $10 \mathrm{~g}$. It is expressed mathematically as:

$$
\operatorname{SAR}=\frac{\mathrm{d}}{\mathrm{dt}}\left(\frac{\mathrm{dW}}{\mathrm{dm}}\right)=\frac{\mathrm{d}}{\mathrm{dt}}\left(\frac{\mathrm{dW}}{\rho \mathrm{dV}}\right)
$$

In terms of the electrical parameters, the SAR can be calculated by

$$
\operatorname{SAR}=\frac{\sigma}{2 \rho}|E|^{2} \ldots
$$

whereE is the amplitude of electric field $(\mathrm{v} / \mathrm{m}), \sigma$ is the conductivity $(\mathrm{s} / \mathrm{m})$, and $\rho$ is the mass density of the tissue. The electrical properties of a biological material vary with absorbed electromagnetic radiation frequency. Dielectric properties of skin and brain tissues are presented in Table 2.

Table 2: The relative permittivity, conductivity and mass density used at 900 and $1800 \mathrm{MHz}$ [13]

\begin{tabular}{|c|c|c|c|c|}
\hline \multicolumn{2}{|c|}{ Properties of Tissue } & Relative Permittivity $\varepsilon_{\mathrm{r}}$ & Conductivity $\sigma(\mathrm{S} / \mathrm{m})$ & $\begin{array}{c}\text { Mass Density } \rho(\mathrm{kg} / \\
\left.\mathrm{m}^{3}\right)\end{array}$ \\
\hline \multirow{2}{*}{ Skin } & $900 \mathrm{MHz}$ & 43.8 & 0.86 & 1000 \\
\cline { 2 - 5 } & $1800 \mathrm{MHz}$ & 38.87 & 1.19 & 1000 \\
\hline \multirow{2}{*}{ Brain } & $900 \mathrm{MHz}$ & 45.8 & 0.77 & 1030 \\
\cline { 2 - 5 } & $1800 \mathrm{MHz}$ & 43.5 & 1.15 & 1030 \\
\hline
\end{tabular}

Several methods have been developed to guide against direct exposure of human beings to electromagnetic radiations which includes the development of phantom models fabricated with various tissue geometries and specially developed tissue equivalent materials and fitted measurement probes[14,15]. Another method used in the determination of SAR which has gained prominence over the years is the finite-difference time-domain (FDTF) method[16,17,18]. Many electromagnetic field simulators have been developed based on the FDTD method to investigate the interaction between human head models and incident plane wave source[19].

\section{The Study Area}

\section{Materials And Methods}

The study area is a hospital located in Ibadan, Nigeria, then the largest city in West Africa. It is located on coordinates $7^{\circ} 24^{\prime} 07^{\prime \prime}$ Nand $03^{\circ} 54^{\prime} 04^{\prime \prime}$ E. Measurements were taken in a representative manner at the study area to include clinical areas, residential areas, business areas and academic areas. The study area was chosen for this study more particularly to provide a baseline data for radiofrequency exposure in the study area. Although radiofrequency interference (RFI) has been observed in some medical device in close proximity with 
cell phone [20,21], a look at the level of radiofrequency field emanating from base stations and estimation of its potential hazard may also be useful for future studies.

\section{Measurement}

Electric field strengths were monitored via a spectrum analyzer for GSM radiofrequency radiation. The spectrum analyzer was used with an omni directional antenna which has the capacity for radial isotropic measurements between $700 \mathrm{MHz}$ to $2.5 \mathrm{GHz}$. Measurements were taken for all GSM Operators in the study area taking into consideration the allocated frequency band by the Nigerian Communications Commission (NCC).There are five operators each in the $900 \mathrm{MHz}$ and $1800 \mathrm{MHz}$ frequency band. For the purpose of this study, the five operators in each band are coded (Op 1 to Op 5) as presented in the NCC frequency spectrum allocation in Table 3.

Table 3: NCC Frequency Spectrum Allocation

\begin{tabular}{|c|c|c|c|c|c|}
\hline \multicolumn{6}{|c|}{$900 \mathrm{MHZ}$} \\
\hline $\begin{array}{c}\text { Operator } \\
\text { Transmitting }\end{array}$ & $\begin{array}{l}\text { Etisalat } \\
\text { (Op 1) }\end{array}$ & $\begin{array}{l}\text { MTel } \\
\text { (Op 2) }\end{array}$ & $\begin{array}{c}\text { Glo } \\
\text { (Op 3) }\end{array}$ & $\begin{array}{l}\text { MTN } \\
\text { (Op 4) }\end{array}$ & $\begin{array}{l}\text { Zain } \\
\text { (Op 5) }\end{array}$ \\
\hline Frequency & $935-940$ & $940-945$ & $945-950$ & $950-955$ & $955-960$ \\
\hline \multicolumn{6}{|c|}{ 1800MHZ } \\
\hline $\begin{array}{l}\text { Operator } \\
\text { Transmitting }\end{array}$ & $\begin{array}{l}\text { MTel } \\
\text { (Op 1) }\end{array}$ & $\begin{array}{c}\text { Glo } \\
(\mathrm{Op} 2)\end{array}$ & $\begin{array}{l}\text { MTN } \\
\text { (Op 3) }\end{array}$ & $\begin{array}{l}\text { Zain } \\
\text { (Op 4) }\end{array}$ & $\begin{array}{l}\text { Etisalat } \\
(\text { Op 5) }\end{array}$ \\
\hline Frequency & $1805-1820$ & $1820-1835$ & $1835-1850$ & $1850-1865$ & $1865-1880$ \\
\hline
\end{tabular}

The field strength measurements were averaged over a six minute period in compliance with the ICNIRP reference level [7].

\section{Results And Discussion}

Measurement of GSM 900 and GSM 1800 field strengths took place within the premises of a teaching hospital in Ibadan, Nigeria. The maximum electric field strength values of $900 \mathrm{MHz}$ Spectrum allocation and their distributions in thirty measurement sites for the five Operators within the spectrum are shown in Fig. 1.

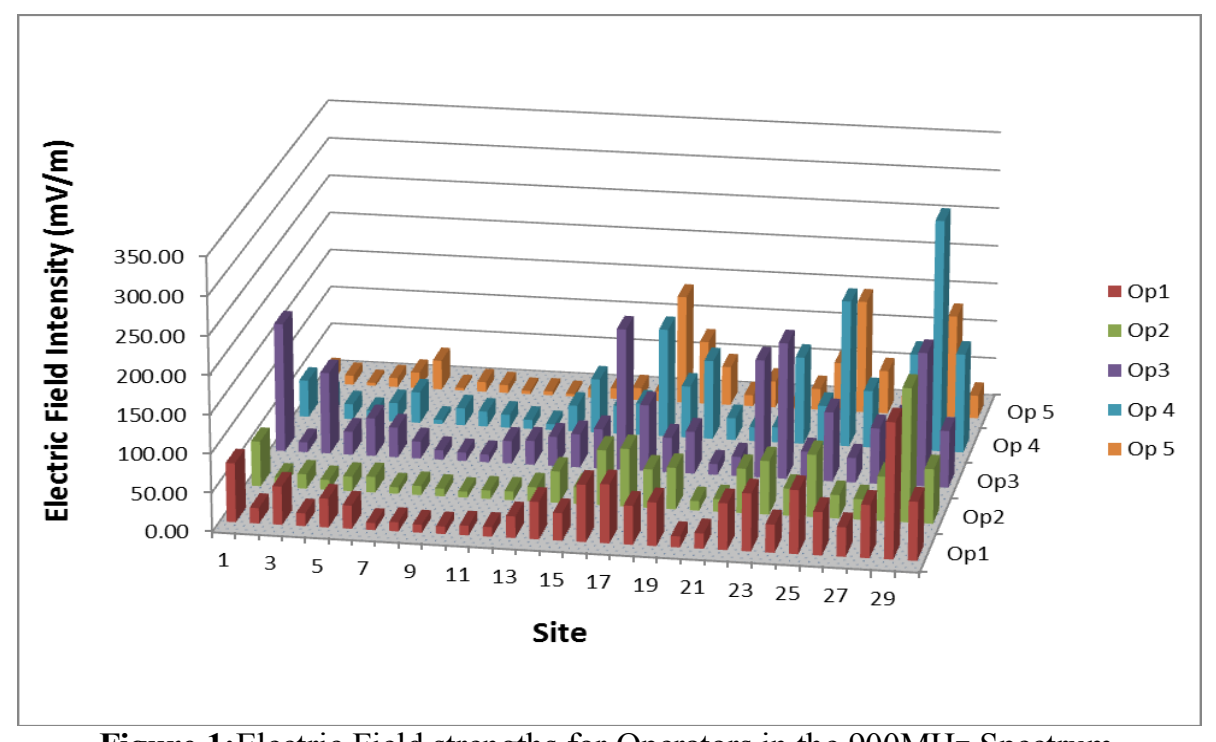

Figure 1:Electric Field strengths for Operators in the 900MHz Spectrum

In the $900 \mathrm{MHz}$ spectrum allocation, Operator 4 radiates the most with maximum exposure of 301.05 $\mathrm{mV} / \mathrm{m}$ and a mean exposure of $61.06 \mathrm{mV} / \mathrm{m}$ while Operator 5 radiates the least with a maximum exposure of $146.91 \mathrm{mV} / \mathrm{m}$ and a mean exposure of $33.95 \mathrm{mV} / \mathrm{m}$. Table 4 summarized the exposure levels in the $900 \mathrm{MHz}$ spectrum allocation.

Variations in the radiofrequency fields are attributable to reflection, refraction and diffraction of electromagnetic radiation to a large number of scatterers and absorbing objects around the measurement site such as buildings, trees, vehicles etc. Buildings provide a strong shadowing effect to electromagnetic fields [22, 23]. 
Hazard estimation from Radiofrequency Radiation in a Nigerian Teaching Hospital from ...

Table 4: Exposure results obtained for $900 \mathrm{MHz}$ Spectrum allocation

\begin{tabular}{|c|c|c|c|c|c|c|}
\hline \multicolumn{7}{|c|}{$900 \mathrm{MHz}$} \\
\hline Operator & $\begin{array}{c}\text { Minimum } \\
\text { Exposure } \\
(\mathrm{mV} / \mathrm{m})\end{array}$ & $\begin{array}{c}\text { Mean } \\
\text { Exposure } \\
(\mathrm{mV} / \mathrm{m})\end{array}$ & $\begin{array}{c}\text { Maximum } \\
\text { Exposure } \\
(\mathrm{mV} / \mathrm{m})\end{array}$ & $\begin{array}{l}\text { Standard } \\
\text { Deviation } \\
(\mathrm{mV} / \mathrm{m})\end{array}$ & $\begin{array}{l}\text { Percentage of } \\
\text { Exposure to } \\
\text { Reference Level }\end{array}$ & $\begin{array}{r}\text { Max } \\
\text { ICNIRP }\end{array}$ \\
\hline Op 1 & 9.12 & 45.18 & 174.19 & 33.82 & & $0.42 \%$ \\
\hline Op 2 & 7.77 & 38.66 & 172.35 & 34.08 & & $0.42 \%$ \\
\hline Op 3 & 10.09 & 65.10 & 183.25 & 53.26 & & $0.44 \%$ \\
\hline Op 4 & 5.49 & 61.06 & 301.05 & 63.85 & & $0.73 \%$ \\
\hline Op 5 & 1.94 & 33.95 & 146.91 & 40.33 & & $0.36 \%$ \\
\hline
\end{tabular}

Generally, Operators in the $1800 \mathrm{MHz}$ spectrum has lesser exposure compared to operators in the 900 $\mathrm{MHz}$ spectrum with the maximum exposure of $241.97 \mathrm{mV} /$ mand a mean exposure of $56.01 \mathrm{mV} / \mathrm{m}$ obtained for operator 3 as shown in table 5. Figure 2 presents the exposures due to the five operators in the $1800 \mathrm{MHz}$ spectrum allocation. Operators 4 and 5 have the least exposure with average exposures of $32.49 \mathrm{mV} / \mathrm{m}$ and $25.76 \mathrm{mV} / \mathrm{m}$ respectively. At some measurement sites, the exposures due to these two operators were almost at the noise floor of the spectrum.

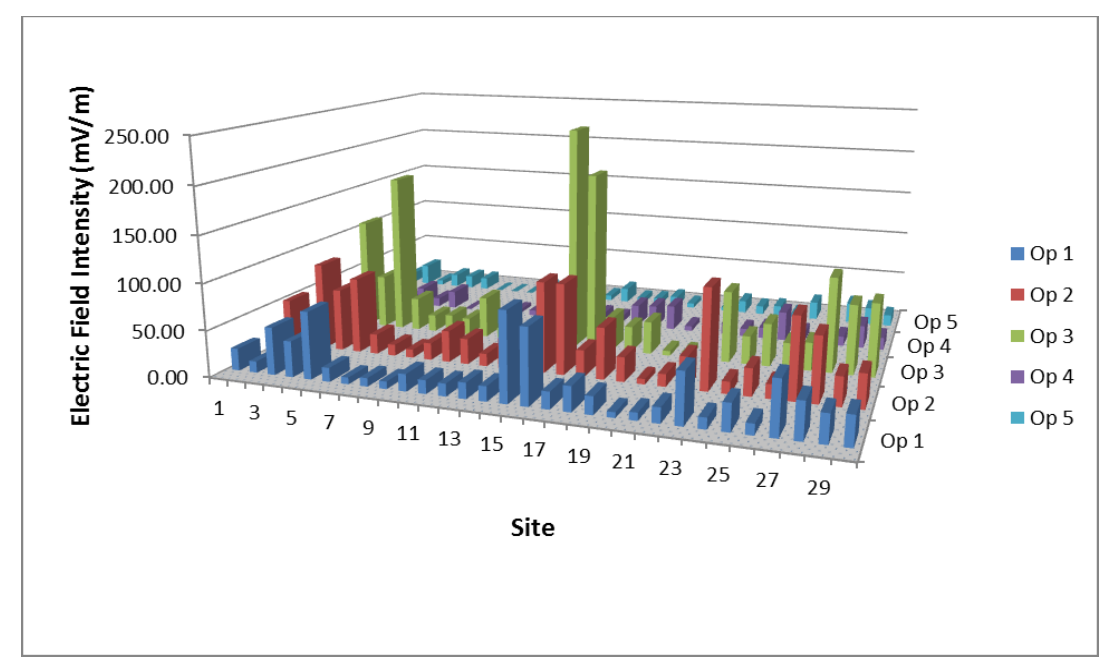

Figure 2:Electric Field Intensity by 5 Operators in the $1800 \mathrm{MHz}$ Spectrum

Overall assessment of the exposures in the $900 \mathrm{MHz}$ and $1800 \mathrm{MHz}$ spectrum allocation show that the power densities are much less than the ICNIRP reference level as shown in table 3 and table 4.

Table 5: Exposures results obtained for $1800 \mathrm{MHz}$ Spectrum allocation

\begin{tabular}{cccccc}
\hline Operator & $\begin{array}{c}\text { Minimum } \\
\text { Exposure } \\
(\mathrm{mV} / \mathrm{m})\end{array}$ & $\begin{array}{c}\text { Mean } \\
\text { Exposure } \\
(\mathrm{mV} / \mathrm{m})\end{array}$ & $\begin{array}{c}\text { Maximum } \\
\text { Exposure } \\
(\mathrm{mV} / \mathrm{m})\end{array}$ & $\begin{array}{c}\text { Standard } \\
\text { Deviation } \\
(\mathrm{mV} / \mathrm{m})\end{array}$ & $\begin{array}{l}\text { Percentage of Max Exposure } \\
\text { to ICNIRP Reference Level }\end{array}$ \\
Op 1 & 5.82 & 28.40 & 94.98 & 22.84 & $0.16 \%$ \\
Op 2 & 5.82 & 41.73 & 107.97 & 30.81 & $0.19 \%$ \\
Op 3 & 5.14 & 56.01 & 241.97 & 57.00 & $0.41 \%$ \\
Op 4 & 0.00 & 12.15 & 32.49 & 8.32 & $0.06 \%$ \\
Op 5 & 0.00 & 10.99 & 25.76 & 8.32 & $0.04 \%$ \\
\hline
\end{tabular}

The estimated SARs due to each operator using the parameters for the skin and brain provided in table 2 are presented in table 6. Estimated SAR for the skin ranges from $0.63 \mu \mathrm{W} / \mathrm{kgto} 39.00 \mu \mathrm{W} / \mathrm{kg}$, while the estimated SAR for the brain ranges from $0.59 \mu \mathrm{W} / \mathrm{kg}$ to $33.90 \mu \mathrm{W} / \mathrm{kg}$.

Table 6:Estimated SAR to the skin and brain

\begin{tabular}{llccccc}
\hline & \multicolumn{5}{c}{ Estimated SAR $\left(\times \mathbf{1 0}^{-\mathbf{6}} \mathbf{W} / \mathbf{k g}\right)$} \\
\hline \multirow{3}{*}{ Skin } & & Op 1 & Op 2 & Op 3 & Op 4 & Op 5 \\
\multirow{3}{*}{ Brain } & $900 \mathrm{MHz}$ & 13.00 & 12.80 & 14.40 & 39.00 & 9.20 \\
& $1800 \mathrm{MHz}$ & 5.37 & 6.94 & 34.80 & 0.63 & 0.39 \\
& $900 \mathrm{MHz}$ & 11.30 & 11.10 & 12.60 & 33.90 & 8.07 \\
& $1800 \mathrm{MHz}$ & 5.04 & 6.51 & 32.70 & 0.59 & 0.37 \\
\hline
\end{tabular}

Using equations (1) and (2), the absorption coefficient and penetration depth in skin and brain tissues were obtained. These results are presented in table 7 for frequencies $900 \mathrm{MHz}$ and $1800 \mathrm{MHz}$. 
Hazard estimation from Radiofrequency Radiation in a Nigerian Teaching Hospital from ...

Table 7: Absorption Coefficients and penetration depth in Skin and Brain tissues

\begin{tabular}{|c|c|c|c|}
\hline & Frequency & $\begin{array}{l}\text { Absorption coefficient } \\
\alpha\left(\mathrm{cm}^{-1}\right)\end{array}$ & Penetration depth $\delta(\mathbf{c m})$ \\
\hline \multirow[t]{2}{*}{ Skin } & $900 \mathrm{MHz}$ & 0.24 & 4.16 \\
\hline & $1800 \mathrm{MHz}$ & 0.36 & 2.81 \\
\hline \multirow[t]{2}{*}{ Brain } & $900 \mathrm{MHz}$ & 0.21 & 4.72 \\
\hline & $1800 \mathrm{MHz}$ & 0.33 & 3.07 \\
\hline
\end{tabular}

\section{Conclusion}

The level of radiofrequency radiation in the measurement sites were found to be far below the ICNIRP reference level. The maximum instantaneous electric field intensities of $301.05 \pm 63.85 \mathrm{mV} / \mathrm{m}$ and $241.49 \pm$ $57.00 \mathrm{mV} / \mathrm{m}$ were obtained for GSM900 and GSM1800 respectively. Estimation of the specific energy absorption rate (SAR) yield $39.00 \mu \mathrm{W} / \mathrm{kg}$ and $34.80 \mu \mathrm{W} / \mathrm{kg}$ for the skin, while that of the brain yield $33.90 \mu \mathrm{W} /$ $\mathrm{kg}$ and $32.70 \mu \mathrm{W} / \mathrm{kg}$ for GSM 900 and GSM 1800 respectively. The skin penetration depth for the worst case of exposure was obtained as $4.16 \mathrm{~cm}$. Exposures in the study area are below the ICNIRP reference level.

The study showed that worst case exposures in the $900 \mathrm{MHz}$ and $1800 \mathrm{MHz}$ spectraare $0.73 \%$ and $0.41 \%$ of the ICNIRP reference level respectively. Irrespective of the levels of radiofrequency radiation, there have been several reports on the biological effects of radiofrequency radiation. This calls for the need for protection against excessive exposure electromagnetic radiations.

\section{Acknowledgements}

This work was supported by the Department of Physics, University of Ibadan, Nigeria. Many thanks to Prof. I.P. Farai whose support and guidance contributed in no small measure to the success of this work.

\section{References}

[1]. J.J. Popoola, I.O. Megbowon, V.S.A. Adeloye. Performance Evaluation and Improvement on Quality of Service of Global System for Mobile Communications in Nigeria.Journal of Information Technology Impact, 9(2): 2009,91-106.

[2]. Edumed. Latin American Experts Committee on High Frequency Electromagnetic Fields and Human Health Scientific Review on Non-Ionizing Electromagnetic Radiation in the Radiofrequency Spectrum and its Effects on Human Health, 2010.

[3]. H. Cember and T. Johnson. Introduction to Health Physics. 2009 (McGraw-Hill. ISBN 978-0-07-142308-3, 4th Ed).

[4]. IUPAC Compendium of Chemical Terminology, 1997. $2^{\text {nd }}$ Ed. Retrieved from www.old.iupac.org/goldbook/D01605.pdf on $15 / 07 / 14$.

[5]. S. Seker,and G. Apaydin. "Effects of Electromagnetic Fields on Human Beings and Electronic Devices", $1^{\text {st }}$ International Conference on Electronics and Computer, Bishkek, Kyrgyzstan, Apr. 2004.

[6]. P. Bernardi, M. Canagnaro, and E. Piuzzi. Specific Absorption Rate and Temperature Elevation in a Subject Exposed in the FarField of Radiofrequency Sources operating in the 10-900MHz Range. IEEE Transactions on Biomedical Engineering, 50(3):2003, 295-304

[7]. Scientific Committee on Emerging and Newly Identified Health Risks, Health Effects of EMF, (SCHNHR, EC, Brussels), 2009.

[8]. ICNIRP. Guidelines for Limiting Exposure to Time-Varying Electric, Magnetic and ElectromagneticFields (up to 300 GHz), ICNRP Guidelines, 74(4): 1998, 494-522.

[9]. A. Maes, M. Collier, D. Slaets, and L. Verschaeve. Cytogenetic effects of microwaves from mobile communication frequencies (954 MHz). Electromagnetic Biology 14: 1995, 91-98.

[10]. O.M. Garson, T.L.McRobert, L.J. Campbell, B.A. Hocking, and I. Gordon. A chromosomal study of workers with long term exposure to radiofrequency radiation. Med. J. Aust. 165: 1999, 289-292.

[11]. A.A. Otitoloju, V.O.Osunkalu, I.A.Obe, O.A.Adewale, and O.R. Akinde. Level of Radiofrequency (RF) Radiations from GSM Base Stations and its Biological Effects on Albino Mice, Musmusculus. J. Appl. Sci. Environ. Manage. 14 (3): 2010,87 - 93.

[12]. H. Cember and T. Johnson. Introduction to Health Physics. 2009 (McGraw-Hill. ISBN 978-0-07-142308-3, 4th Ed).

[13]. A. Z. El Dein and A. Alaeddin. Specific Absorption Rate (SAR) induced in Human Heads of various sizes when using a Mobile Phone. Proceedings of the World Congress on Engineering, June 30 - July 2, 2010, London, U.K. Vol. 1. ISBN: 978:988-17012-9-

[14]. E.R. Adair and R.C. Petersen. Biological effects of radiofrequency/microwave radiation review. IEEE Transactions on Microwave Theory Technology 50 (3): 2002, $953-962$.

[15]. M. Zhang, and A. Alden. Calculation of Whole-Body SAR from a 100MHz Dipole Antenna.Progress in Electromagnetics Research, 119: 2011, 133-153

[16]. S. Khalatbari, D. Sardari, A.A.Mirzaee, and H.A. Sadafi. Calculating SAR in Two Models of the Human Head Exposed to Mobile Phones Radiations at 900 and 1800 MHz.Progress in Electromagnetics Research Symposium 2006, Cambridge, USA, March 26-29, 2006.

[17]. A. Hirata, O. Fujiwara, T.Nagaoka, and S. Watanabe. Estimation of Whole-Body SARs in Human Models Due to Plane-Wave Exposure at Resonance frequency. Electromagnetic Compatibility, IEEE Transactions on, 52(1): 2010, 41-48.

[18]. S. Paker, and K. Sergi. FDTD Evaluation of the SAR Distribution in a Human Head near a Mobile Cellular Phone. Electrik 6(3): $1998,227-242$.

[19]. M. Martinez-Burdalo, A. Martin, M.Anguiano, and R. Villar. Comparison of FDTD-Calculated Specific Absorption Rate in Adults and Children when using a Mobile Phone at 900 and 1800MHz. Phys. Med. Biol. 49: 2004, 345-354.

[20]. V. Purushothaman, N.Vignesh, and S. Vijayakumar. FDTD Computation of SAR Distributions in Human Head for Mobile Phones.International Journal of Scientific Engineering and Technology, 2(11): 2013, 1069-1073.

[21]. S. Helhel, Z.A.Colak, and S. Ozen. Distance and Location of both Mobile Phones and Health Care Units: Determines the Interference Level. American Journal of Biomedical Engineering, 1(2):2011, 78-82.

[22]. S.E. Lapinsky and A.C. Easty. Electromagnetic interference in Critical Care. Journal of Critical Care, 21: 2006, 267-270 
[23]. Y. Ajiboye, and Osiele, M. O. Assessment of Spatial Exposure to RF Radiation due to GSM 900 and GSM1800-A Case Study of UCH, Ibadan, Nigeria. IOSR Journal of Applied Physics, 4:2013, 44-48.

[24]. S. Miclausand P. Bechet. Estimated and Measured Values of the Radiofrequency Radiation Power Density around Cellular Base Stations. Rom. Journ. Phys., 52(3-4): 2007, 429-440. 